\title{
Change in asthma and COPD prescribing by Italian general practitioners between 2006 and 2008
}

\author{
*Mario Cazzola ${ }^{a}$, Andrea Segreti ${ }^{a}$, Germano Bettoncellib, Luigino Calzettaa \\ Claudio Cricellib, Franco Pasquac, Paola Rogliani ${ }^{a}$
}

\author{
${ }^{\text {a }}$ Department of Internal Medicine, University of Rome Tor Vergata, Rome, Italy \\ ${ }^{\mathrm{b}}$ Health Research Institute, Italian College of General Practitioners, Florence, Italy \\ 'Pulmonary Rehabilitation Group, San Raffaele Pisana Hospital, Rome, Italy
}

Received 30th June 2010; revised 21st November 2010; accepted 31st January 2011; online 20th April 2011

\begin{abstract}
Aims: To explore the trend in prescribing of drugs classified within the R03 therapeutic pharmacological subgroup (drugs for obstructive airway diseases) of the Anatomical Therapeutic Chemical (ATC) classification.

Methods: Comparison of GP-collected data on physician-patient contacts and drug prescriptions for asthma and COPD in 2006 and 2008.

Results: Compared to 2006, in 2008 patients with COPD were prescribed more long-acting bronchodilators; use of tiotropium increased, whilst use of long-acting $\beta_{2}$-agonists (LABAs) and short-acting antimuscarinic agents decreased. However, $55.9 \%$ of patients in 2006 , and $47.8 \%$ in 2008 , received an inhaled corticosteroid (ICS), mainly as a LABA/ICS fixed combination inhaler. Compared to 2006 , in 2008 there were increased prescriptions of LABAICS fixed combination inhalers for asthma, but only $54.5 \%$ of all prescriptions included an ICS. This could explain the large use of short-acting $\beta_{2}$-agonists, a marker of poor asthma control. Remarkably, LABA/ICS fixed combination inhalers were prescribed more frequently in COPD than in asthma.

Conclusions: Our data indicate that adherence to guidelines is still low. Patients with asthma and COPD are undertreated by Italian GPs, with a trend to a change in COPD prescribing likely driven by new scientific information.

(C) 2011 Primary Care Respiratory Society UK. All rights reserved.

M Cazzola et al. Prim Care Respir J 2011; 20(3): 291-298

http://dx.doi.org/10.4104/pcrj.2011.00033
\end{abstract}

Keywords asthma, COPD, general practitioners, treatment, prescribing, Italy, bronchodilators, inhaled corticosteroid

\section{Introduction}

There are now many guidelines that provide direction for the diagnosis and management of asthma and chronic obstructive pulmonary disease (COPD).$^{1-4}$ Asthma treatment guidelines aim to ensure that control is gained and maintained using a stepwise approach, tailoring treatment both to the severity of asthma and to the individual day-to-day needs of the patient, employing the lowest effective medication dose. ${ }^{1-2}$ Current COPD guidelines also advocate a stepwise approach to treatment based on disease severity, with more of a focus towards decreasing symptoms and/or preventing disease progression..$^{3-4}$

Bronchodilators, inhaled corticosteroids (ICS), and other anti-inflammatory agents form the basis of treatment for asthma and COPD..$^{1-4}$ However, although the medications used for both conditions are similar, the goals and targets of therapy are different. ${ }^{5,6}$ In general, therapy for asthma is mainly targeted at reducing inflammation, ${ }^{1,2}$ whereas for COPD treatment is mainly directed at relief of symptoms. ${ }^{3,4}$

Furthermore, despite their different pathophysiology, asthma and COPD have certain similarities and it is sometimes not easy to differentiate between them especially in patients over the age of 40 or in those patients with spirometry that shows incomplete reversibility. Various studies have confirmed that for both asthma and COPD there are problems with underdiagnosis, wrong diagnosis, a high percentage of patients with overlapping symptoms, and little observance of good clinical practice guidelines. ${ }^{7-9}$ This is important, because a misdiagnosis of asthma or COPD leads to inadequate patient management and

\footnotetext{
* Corresponding author: Professor Mario Cazzola, Dipartimento di Medicina Interna, Università di Roma Tor Vergata, Via Montpellier 1, 00133 Roma, Italy. Tel: +39 0620903615 Fax: +39 0672596207 E-mail: mario.cazzola@uniroma2.it
} 
escalating healthcare costs. Asthma and COPD still remain underdiagnosed and under- or badly treated worldwide, ${ }^{9-14}$ and there remains a substantial discrepancy between the actual care provided and guideline-defined best treatment in patients with mild to moderate asthma or COPD in primary care. . $^{15,16}$

There have been few studies investigating the quality of asthma and COPD care in Italian general practice. One study showed that a high number of patients with asthma and COPD have poor control of their disease, and suggested that Italian general practitioners (GPs) may misunderstand and misclassify the real level of disease severity and were therefore not modifying pharmacological treatment accordingly. ${ }^{17}$ We have shown previously that primary care management of stable COPD in Italy often does not follow guidelines, ${ }^{18}$ in particular, GPs usually prescribe treatment without the prior use of spirometry, and/or without taking into account the severity of airway obstruction.

The present study was conducted to identify the usual patterns of treatment for asthma and COPD in Italian primary care centres, to investigate whether management was consistent with asthma and COPD management guidelines, and finally, whether there were changes in GP prescribing behaviour between 2006 and 2008 given the Food and Drug Administration (FDA) warning on the use of long-acting $\beta_{2}-$ agonists (LABAs) in asthma ${ }^{19}$ and the publication of the results from the COPD "mega-trials". ${ }^{20-22}$

\section{Material and methods}

\section{Data collection}

We conducted a population-based retrospective study using information obtained from the Health Search database (HSD) owned by the Italian College of General Practitioners (SIMG). Established in 1998 with the primary aim of carrying out observational studies on the incidence and prevalence of chronic diseases with the input of GPs who participate on a voluntary basis, the HSD contains information provided by more than 650 Italian GPs and includes data on more than 900,000 individuals over 14 years old (since 1978 the Italian National Health Service has provided paediatric primary care for children up to 14 years of age through the use of community-based paediatricians).

After intensive training, all participating GPs had to use specially designed software to record data during their normal daily clinical practice (Millewin). The software system codes all the diagnostic records by using the Classification of Diseases, Ninth Revision, Clinical Modification (ICD-9-CM). Prescription records are also coded according to the anatomical therapeutic chemical (ATC) classification system. Data are recorded in the HSD with the consent of the patient, lawfully stored, managed according to privacy rules, and can be used for scientific studies without any further authorisation from an ethics committee.
Before using any data resource, particularly one that is based on computer records, it is necessary to determine the quality and completeness of the available information. Therefore, HSD data are subject to a range of quality checks. Any variations within agreed ranges are investigated and submitted to each participating GP. Physicians who fail to meet standard quality criteria are not considered for epidemiological studies. ${ }^{8}$ Comparative analyses have demonstrated the validity of the information gathered in the HSD. ${ }^{9}$

We selected 400 GPs homogeneously distributed across all Italian areas with a patient population of 617,280 individuals aged over 14 years at the end of December 2006, and 500 GPs with a patient population of 735,988 individuals aged over 14 at the end of December 2008, so that the patients were representative of the whole Italian population. This selection ensured the required data quality. However, we were unable to compare data from the same group of GPs due to abandonment of the HSD by several GPs and the introduction of new GPs in the HSD between 2006 and 2008.

\section{Ascertainment of asthma and COPD drug prescription}

Cases of asthma and COPD were identified on the basis of the ICD-9 code (493 for asthma, and 491.2 and 496 for COPD). The number of patients classified on the basis of the ICD-9 code 493.2 (chronic obstructive asthma) was really small and for this reason we have considered them as asthmatic patients. All drugs prescribed were abstracted and codified according to the R03 therapeutic pharmacological subgroup (drugs for obstructive airway diseases) of the ATC classification.

For each group of drugs, we indicate the number of prescriptions as a percentage of the total number of prescriptions for the specific disease and year considered, and the number of prescriptions/patient/year ( $p / p)$.

It is important to highlight that the Italian reimbursement plan allows GPs to prescribe two packages of the same drug/inhaler or one package of two different drugs/inhalers per prescription. A prescription can be dispensed only once and cannot be used for multiple dispensations. Therefore, we report the number of packages of the same drug/inhaler prescribed/patient/year.

\section{Results}

The study population in 2006 consisted of 28,654 patients (4.6\% of the entire population) suffering from asthma and 15,229 patients ( $2.5 \%$ of the entire population) suffering from COPD; in 2008, there were 37,098 asthma patients $(5.04 \%$ of the entire population) and 21,793 COPD patients ( $2.96 \%$ of the entire population).

In 2006, prescriptions of drugs for obstructive airway diseases (ATC code R03) numbered 48,140 (1.68 p/p) for asthma and 48,303 (3.17 p/p) for COPD, while in 2008 they 
were $64,300(1.73 \mathrm{p} / \mathrm{p})$ for asthma and 72,311 (3.31 p/p) for COPD (see Table 1).

In 2006, there were 15,848 prescriptions of bronchodilators for asthma $(32.9 \% ; 0.55 \mathrm{p} / \mathrm{p})$, and 18,506 $(38.3 \% ; 1.21 \mathrm{p} / \mathrm{p})$ for COPD, whereas in 2008 the numbers of prescriptions were $20,099(31.3 \% ; 0.54 \mathrm{p} / \mathrm{p})$ for asthma and $27,906(38.6 \% ; 1.28 \mathrm{p} / \mathrm{p})$ for COPD (see Table 1 and Figures 1 and 2). The percentage of LABA prescribing in asthma was $26.5 \%$ and $23.4 \%$ of all bronchodilators prescribed for asthma in 2006 and 2008, respectively; whilst for COPD, LABAs were $23.6 \%$ and $19.1 \%$ of all bronchodilators prescribed for COPD patients in 2006 and

Table 1. Prescriptions of drugs for obstructive airway diseases (ATC code R03).

For each group of drugs, the \% of prescriptions considering the total number of prescriptions for the specific disease and year considered and the number of prescriptions/patient)year ( $p / p)$ is indicated, while for each class of drugs included in a specific group, the \% of prescriptions considering the total number of prescriptions for that group, disease and year is reported

\begin{tabular}{|c|c|c|c|c|}
\hline & $\begin{array}{l}\text { Asthma } \\
2006\end{array}$ & 2008 & $\begin{array}{l}\text { COPD } \\
2006\end{array}$ & 2008 \\
\hline Total prescriptions & $48,140(1.68 \mathrm{p} / \mathrm{p})$ & $64,300(1.73 \mathrm{p} / \mathrm{p})$ & $48,303(3.17 \mathrm{p} / \mathrm{p})$ & $72,311(3.31 \mathrm{p} / \mathrm{p})$ \\
\hline Bronchodilators & $15,848(32.9 \% ; 0.55 \mathrm{p} / \mathrm{p})$ & $20,099(31.3 \% ; 0.54 \mathrm{p} / \mathrm{p})$ & $18,506(38.3 \% ; 1.21 \mathrm{p} / \mathrm{p})$ & 27,906 (38.6\%; 1.28 p/p) \\
\hline$\beta_{2}$-agonists & $12,404(78.3 \%)$ & $15,153(75.4 \%)$ & $8,079(43.7 \%)$ & $10,444(37.4 \%)$ \\
\hline LABAS & $4,201(26.5 \%)$ & $4,697(23.4 \%)$ & $4,368(23.6 \%)$ & $5,323(19.1 \%)$ \\
\hline SABAS & $8,203(51.8 \%)$ & $10,456(52.0 \%)$ & $3,711(20.1 \%)$ & $5,121(18.3 \%)$ \\
\hline Anticholinergics & $3,140(19.8 \%)$ & $4,656(23.2 \%)$ & $10,123(54.7 \%)$ & $17,187(61.6 \%)$ \\
\hline LAMAs & $1,712(10.8 \%)$ & $3,655(18.2 \%)$ & $6,416(34.7 \%)$ & $14,625(52.4 \%)$ \\
\hline SAMAS & $1,428(9.0 \%)$ & $1,001(5.0 \%)$ & $3,707(20.0 \%)$ & $2,562(9.2 \%)$ \\
\hline SABAs+SAMAs & $304(1.9 \%)$ & $290(1.4 \%)$ & $304(1.6 \%)$ & $275(1.0 \%)$ \\
\hline $\begin{array}{l}\beta_{2} \text {-agonist/ICS fixed } \\
\text { combination }\end{array}$ & $14,624(30.4 \% ; 0.51$ p/p) & $22,775(35.4 \% ; 0.61 \mathrm{p} / \mathrm{p})$ & 13,708 (28.4\%; 0.90 p/p) & $23,501(32.5 \% ; 1.08$ p/p) \\
\hline Salmeterol/fluticasone & $8,230(56.3 \%)$ & $11,924(52.4 \%)$ & $8,495(62.0 \%)$ & $13,635(58.0 \%)$ \\
\hline $\begin{array}{l}\text { Formoterol/beclomethasone } \\
\text { or budesonide }\end{array}$ & $3,059(20.9 \%)$ & $7,253(31.8 \%)$ & $2,308(16.8 \%)$ & $6,217(26.5 \%)$ \\
\hline Salbutamol/beclomethasone & $3,335(22.8 \%)$ & $3,598(15.8 \%)$ & $2,905(21.2 \%)$ & $3,649(15.5 \%)$ \\
\hline ICSs & $10,851(22.5 \% ; 0.38 \mathrm{p} / \mathrm{p})$ & $12,294(19.1 \% ; 0.33 \mathrm{p} / \mathrm{p})$ & $8,487(17.6 \% ; 0.56 \mathrm{p} / \mathrm{p})$ & $11,044(15.3 \% ; 0.51 \mathrm{p} / \mathrm{p})$ \\
\hline Beclomethasone & $5,345(49.3 \%)$ & $6,413(52.2 \%)$ & $4,344(51.2 \%)$ & $6,106(55.3 \%)$ \\
\hline Fluticasone & $2,391(22.0 \%)$ & $2,576(20.9 \%)$ & $1,769(20.8 \%)$ & $2,006(18.2 \%)$ \\
\hline Budesonide & $2,222(20.5 \%)$ & $2,285(18.6 \%)$ & $1,569(18.5 \%)$ & $1,691(15.3 \%)$ \\
\hline Flunisolide & $893(8.2 \%)$ & $1,020(8.3 \%)$ & $805(9.5 \%)$ & $1,241(11.2 \%)$ \\
\hline Xanthines & $2,579(5.4 \% ; 0.09 \mathrm{p} / \mathrm{p})$ & $2,977(4.6 \% ; 0.08 \mathrm{p} / \mathrm{p})$ & $6,630(13.7 \% ; 0.44 \mathrm{p} / \mathrm{p})$ & $8,252(11.4 \% ; 0.38 \mathrm{p} / \mathrm{p})$ \\
\hline Theophylline & $1,594(61.8 \%)$ & $1,795(60.3 \%)$ & $4,525(68.3 \%)$ & $5,398(65.4 \%)$ \\
\hline Doxophylline & $534(20.7 \%)$ & $683(22.9 \%)$ & $1,208(18.2 \%)$ & $1,674(20.3 \%)$ \\
\hline Bamiphylline & $297(11.5 \%)$ & $308(10.3 \%)$ & $717(10.8 \%)$ & $972(11.8 \%)$ \\
\hline Diprophylline & & 1 & & 5 \\
\hline Aminophylline & $48(1.9 \%)$ & $38(1.3 \%)$ & $67(1.0 \%)$ & $82(1.0 \%)$ \\
\hline Other xanthines & $106(4.1 \%)$ & $152(5.1 \%)$ & $113(1.7 \%)$ & $121(1.5 \%)$ \\
\hline Antileukotrienes & $3,853(8.0 \% ; 0.13 \mathrm{p} / \mathrm{p})$ & $5,717(8.9 \% ; 0.15 \mathrm{p} / \mathrm{p})$ & $952(2.0 \% ; 0.06 \mathrm{p} / \mathrm{p})$ & $1,455(2.0 \% ; 0.07 \mathrm{p} / \mathrm{p})$ \\
\hline Montelukast & $3,579(92.9 \%)$ & $5,444(95.2 \%)$ & $822(86.3 \%)$ & $1,312(90.2 \%)$ \\
\hline Zafirlukast & $274(7.1 \%)$ & $273(4.8 \%)$ & $130(13.7 \%)$ & $143(9.8 \%)$ \\
\hline Cromones & $375(0.8 \%, 0.01 \mathrm{p} / \mathrm{p})$ & $410(0.6 \% ; 0.01 \mathrm{p} / \mathrm{p})$ & 11 & 132 \\
\hline Nedocromil & 360 & 406 & & 131 \\
\hline Cromoglicic acid & 15 & 4 & 11 & 1 \\
\hline
\end{tabular}


Figure 1. Changes in prescriptions of drugs for obstructive airway diseases (ATC code R03) in asthma between 2006 and 2008. For each group of drugs, the $\%$ of prescriptions considering the total number of prescriptions for that group and year is reported. ICSs, inhaled corticosteroids

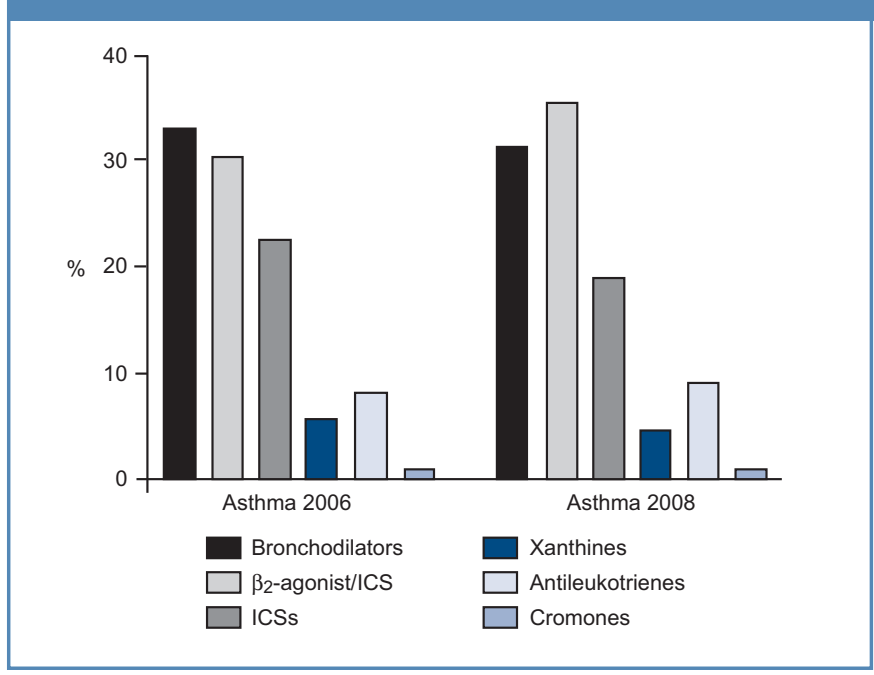

2008, respectively (see Figure 3 ). The percentage of tiotropium prescribed in asthma was $10.8 \%$ and $18.2 \%$ of all bronchodilators prescribed for asthma in 2006 and 2008, respectively; in COPD, tiotropium constituted $34.7 \%$ and $52.4 \%$ of all bronchodilators prescribed for COPD in 2006 and 2008, respectively (see Figure 3).

In 2006, there were $14,624 \quad(30.4 \% ; 0.51 \mathrm{p} / \mathrm{p})$ prescriptions of LABA/ICS fixed combination inhalers in asthma and $13,708(28.4 \% ; 0.90 \mathrm{p} / \mathrm{p})$ in COPD, with salmeterol/fluticasone constituting more than half of all LABA/ICS prescriptions both in asthma (56.3\%) and COPD (62.0\%). In 2008, prescriptions for LABA/ICS combination inhalers were $22,775(35.4 \%, 0.61 \mathrm{p} / \mathrm{p})$ in asthma and $23,501(32.5 \%, 1.08 \mathrm{p} / \mathrm{p})$ in COPD, and again salmeterol/fluticasone constituted more than half of all prescriptions in asthma (52.4\%) and COPD (58.0\%) (see Table 1 and Figures 1 and 2).

In 2006, prescriptions of ICS inhalers were 10,851 $(22.5 \% ; 0.38 \mathrm{p} / \mathrm{p})$ in asthma and $8,487(17.6 \% ; 0.56 \mathrm{p} / \mathrm{p})$ in COPD, whereas in 2008 they were 12,294 (19.1\%; $0.33 \mathrm{p} / \mathrm{p})$ in asthma and 11,044 (15.3\%; $0.51 \mathrm{p} / \mathrm{p}$ ) in COPD (see Table 1 and Figures 1 and 2).

Xanthines were prescribed 2,579 times $(5.4 \% ; 0.09 \mathrm{p} / \mathrm{p})$ in asthma and 6,630 times $(13.7 \% ; 0.44 \mathrm{p} / \mathrm{p})$ in COPD in 2006; in 2008 , there were 2,977 prescriptions $(4.6 \% ; 0.08 \mathrm{p} / \mathrm{p})$ for asthma and 8,252 prescriptions $(11.4 \% ; 0.38 \mathrm{p} / \mathrm{p})$ for COPD (see Table 1 and Figures 1 and 2).

For antileukotrienes, the number of prescriptions for asthma was 3,853 (8.0\%; $0.13 \mathrm{p} / \mathrm{p})$ in 2006 and 5,717 (8.9\%; $0.15 \mathrm{p} / \mathrm{p})$
Figure 2. Changes in prescriptions of drugs for obstructive airway diseases (ATC code R03) in COPD between 2006 and 2008. For each group of drugs, the $\%$ of prescriptions considering the total number of prescriptions for that group and year is reported. ICSs, inhaled corticosteroids

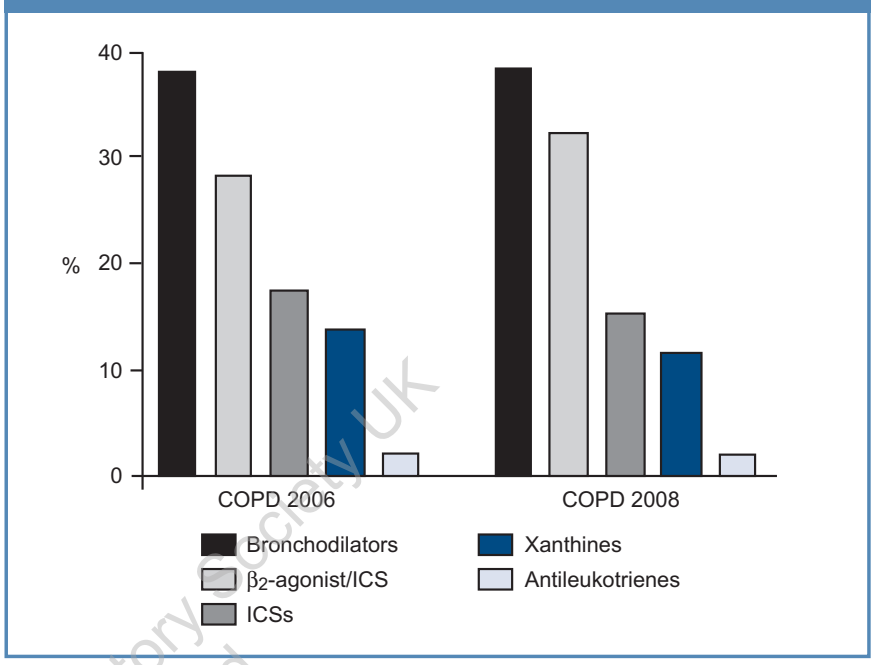

Figure 3. Changes in prescriptions of bronchodilators in asthma and COPD between 2006 and 2008. For each class of drugs, the \% of prescriptions considering the total number of prescriptions for bronchodilators, disease and year is reported. LABAs, long-acting $\beta_{2}$-agonists; SABAs short-acting $\beta_{2}$-agonists; LAMAs, long-acting antimuscarinic agents; SAMAs, short-acting antimuscarinic agents

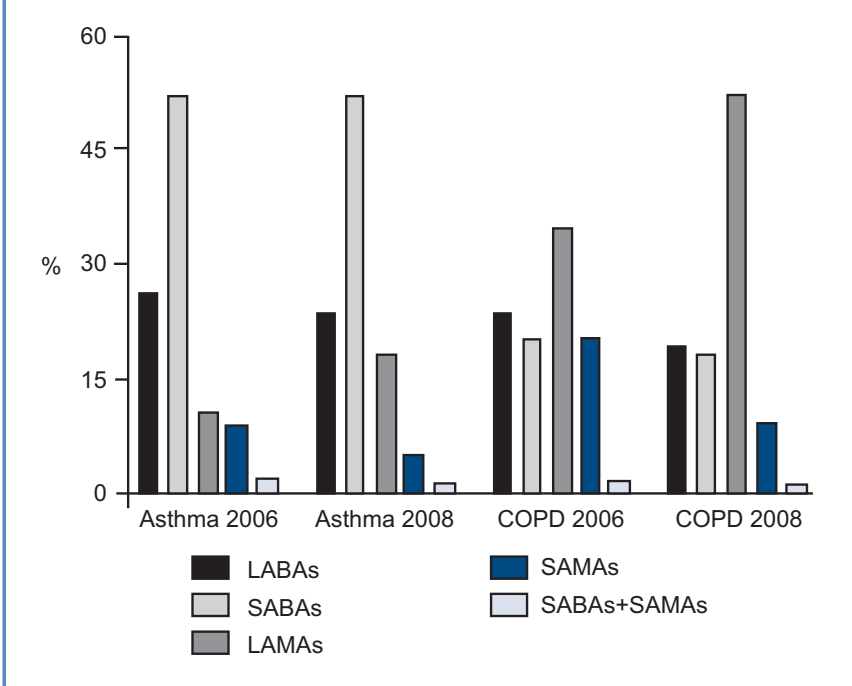

in 2008; for COPD, there were 952 prescriptions (2.0\%; 0.06 $\mathrm{p} / \mathrm{p}$ ) in 2006 and 1,455 (2.0\%; $0.07 \mathrm{p} / \mathrm{p}$ ) in 2008 (see Table 1 and Figures 1 and 2). The number of cromone prescriptions was very low in both 2006 and 2008 (Table 1). 


\section{Discussion}

There are three principal findings arising from this study. Firstly, we observed a small increase in the percentage of patients suffering from both asthma and COPD between 2006 and 2008. However, we cannot conclude that this was due to a real change in disease prevalence or a change in diagnostic habits. One could speculate that widening the base of study GPs in 2008 as compared to 2006 and the replacement of a number of participants in the 2008 survey might have included more motivated physicians thus causing an increase in the study population and increased numbers of subjects suffering from asthma and COPD.

Secondly, application of international guideline recommendations for the treatment of asthma and COPD, ${ }^{1-4}$ although improved, is still inadequate in Italy. In particular, there is off-label prescribing of some classes of drugs such as tiotropium in asthma and antileukotrienes in COPD. In addition, there is over-treatment with ICS when compared with other prescribed drugs in COPD patients; at the time of the study, the GOLD guidelines still recommended that ICS only be added to bronchodilator therapy for COPD patients at stages III (severe) and IV (very severe) - i.e. those patients with an $\mathrm{FEV}_{1} / \mathrm{FVC}$ ratio $<0.70$ and an $\mathrm{FEV}_{1}<50 \%$ predicted who are still having exacerbations. ${ }^{3}$ We have previously examined the same database (HRD) and observed that in this COPD population, spirometry was performed for only one third of cases. ${ }^{18}$ The lack of spirometric data for many patients does not allow us to verify whether those who received ICS met the guideline criteria, but it is highly likely that many COPD patients were prescribed ICS treatment without there being any spirometric evidence to support the prescribing decision.

Thirdly, and most importantly, patients with asthma and COPD are undertreated by Italian GPs. Our study shows that, in 2008, patients with asthma received only 1.54 prescribed packages of controller medication per patient per year, and in particular, 1.22 prescribed packages of ICS/patient/year. Asthma guidelines suggest that the large majority of people with a diagnosis of asthma should be given an anti-inflammatory controller medication for regular use, ${ }^{1,2}$ but the small number of prescriptions of controller medications/patient/year clearly indicates that patients were not being treated on a regular basis. Also, COPD patients had only sporadic treatment (only 3.31 prescribed packages/patient/year); COPD guidelines affirm that the overall approach to managing stable COPD should be characterised by an increase in treatment depending on the severity of the disease and the clinical status of the patient - in any case, reduction of therapy once symptom control has been achieved is not normally possible in COPD. ${ }^{3,4}$ In terms of these recommendations, we believe that many patients were not being treated at all, or that the treatment was arbitrarily discontinued.
Apparently, the results of the COPD "mega-trials"20-22 seem to have induced a real, albeit small, change in approach to the treatment of COPD, whereas the FDA warning on LABAs ${ }^{19}$ has not influenced the prescribing behaviour of Italian GPs for the treatment of asthma.

At the present time, it is impossible to determine from the analysis of the HSD whether there was only inadequate drug prescription by GPs or whether the majority of patients with asthma or COPD did not require medical intervention. If the first hypothesis were true, it would be necessary to identify the barriers that prevent adherence of Italian GPs to international guidelines. It has been suggested that the four major barriers to guideline adherence are: lack of agreement; lack of self-efficacy; lack of outcome expectancy; and mainly, inertia from previous practice. ${ }^{23}$ In fact, Italian physicians prefer other sources of information, especially their own and their colleagues' experience, to practice guidelines. ${ }^{24}$ The most prominent barrier perceived by GPs to their applying the key recommendations of guidelines is often a lack of agreement with the actual guideline recommendations. It is our opinion that GPs often disagree with recommendations because they disagree with the underlying evidence provided or they feel that it isn't clear why the guidelines should apply to them. In addition, they perceive some recommendations to be non-applicable because of the heterogeneity of patient populations. ${ }^{25}$ Most recent guidelines for asthma and COPD treatment make recommendations based on evidence collected from large randomised clinical trials and/or systematic reviews. ${ }^{1-4}$ However, even though a large randomised trial containing a large number of patients can provide highly statistically significant evidence in favour of one drug compared to another, this does not necessarily imply that the results can be extrapolated to a larger, less selected patient population. It has been documented that typical clinical study patients with asthma or COPD represent a very small fraction of the patient population being treated by clinicians in everyday practice, regardless of whether the doctors are pulmonary physicians or GPs. ${ }^{26}$

A crucial factor is that GPs often have to negotiate their relationship with patients, weighing the theoretical appropriateness of a decision with the patient's values and expectations and with risks of legal liability. ${ }^{24}$ Moreover, Italian GPs are paid on a per capita basis; hence, they are financially dependent on their number of listed patients and are probably more careful about not "disappointing" them. ${ }^{24}$ Daily experience shows that patients will often not accept chronic drug treatment as required by guidelines for the management of asthma and COPD.

It is too simplistic to blame undertreatment on the professional shortcomings of GPs. It is possible that the undertreatment of asthma and COPD reported in our study was due to the majority of patients with asthma or COPD not asking 
for medical intervention. A recent epidemiological study indicated that most of the Italian general population who report the presence of respiratory symptoms/diseases or impaired lung function do not use medicines. ${ }^{27}$ This is not just an Italian phenomenon. For example, Bottema studied the prevalence of asthma or COPD in Dutch general practice, and concluded that a major reason for inadequate treatment was patient drop-out - a life-time asthma/COPD patient "career" lasted between 1 and 10 years, with the majority clustering around 2-4 years. ${ }^{28}$

Understanding the real reason for the pharmacological undertreatment of patients observed in this study will require a different methodological approach. Nonetheless, the present analysis permits a number of considerations about the specific prescribing practices exhibited by Italian GPS.

Firstly, people with COPD exhibited the highest use of drugs for obstructive airway diseases. This is not surprising, considering that most patients present to their GP mainly because of chronic or persistent respiratory signs and symptoms; asthma is a common chronic disorder but is characterised by variable (although recurrent) symptoms, while COPD is characterised by airflow limitation that is poorly reversible and which gets progressively worse over time causing persistent shortness of breath.

As expected, COPD patients made more extensive use of bronchodilators in general, and long-acting bronchodilators in particular. In contrast, the use of short-acting $\beta_{2}$-agonists (SABAs) was prevalent in patients with asthma. SABAS are bronchodilators that are recommended only for as-needed use in asthma, ${ }^{1,2}$ and excess use should be interpreted as a marker of poor asthma control. The prescription of LABA inhalers (as single agents) in asthma was rather high both in 2006 and 2008 (8.7\% of all asthma prescriptions in 2006 and $7.3 \%$ in 2008). Unfortunately, it is impossible to determine from this analysis if there were asthmatics who were receiving a LABA as monotherapy without concomitant ICS - which would constitute suboptimal therapy as reported by Nelson et al. ${ }^{29}$ There was a substantial increase in the use of tiotropium in COPD in place of LABAs but particularly instead of short-acting antimuscarinic agents. The prescription of long-acting bronchodilators for COPD were consistent with the recommendations of guidelines, ${ }^{3,4}$ and the increase in tiotropium prescribing was likely due to the growing body of evidence published in 2007 and 2008 that indicated the fundamental role of this long-acting antimuscarinic agent in the symptomatic treatment of COPD. ${ }^{22,30}$

There was an increase in the number of prescriptions of LABA/ICS fixed combination inhalers for the management of asthma between 2006 and 2008. This was due principally to an increase in prescriptions of combination inhalers containing formoterol with beclomethasone or budesonide. This increase is likely related to the launch into the Italian market in 2007 of the
LABA/ICS combination formoterol/beclomethasone developed by Chiesi Farmaceutici, an Italian drug company. Although not yet approved for use in COPD, this combination has probably gained prescriptions even in this disease. Nonetheless, salmeterol/fluticasone was still the most prescribed fixed LABA/ICS combination both in asthma and COPD; it is noteworthy that it represented $17.6 \%$ in 2006 and $18.9 \%$ in 2008 of all prescriptions in COPD, and this happened even in the presence of additional prescription of ICS (which amounted to $17.6 \%$ in 2006 and $15.3 \%$ in 2008 of all prescriptions for this disease). This means that $55.9 \%$ of all COPD patients in 2006 and still $47.8 \%$ in 2008 received treatment with ICS. The current GOLD guideline recommendations as regards ICS prescribing have already been discussed. The evident reduction in the prescription of ICS for COPD between 2006 and 2008 likely indicates an improved therapeutic approach by Italian GPS to their prescribing for patients with COPD.

It is surprising that only $52.9 \%$ in 2006 and $54.5 \%$ in 2008 of all prescriptions for asthma included an ICS. This finding indicates a substantial underuse of ICS despite the strong evidence that ICS are beneficial in treating asthma and that their underuse is responsible for poorer outcomes. However, it is impossible to determine from our analysis whether the underuse of ICS was related specifically to excessive SABA use.

The prescription of xanthines (mainly theophylline, doxofylline, and bamifylline) in COPD was greater than expected (13.7\% of all prescriptions) in 2006, given that they have been relegated to third-line therapy in COPD guidelines because of their frequent side effects and relatively low efficacy. ${ }^{3,4}$ By 2008 , their use had decreased to $11.4 \%$. As in many chronic diseases, in the treatment of COPD there is an important gap between guideline recommendations and the use of prescribed medications in clinical practice. ${ }^{31}$ Nonetheless, we do not believe that the use of xanthines in COPD is a major violation of guidelines. ${ }^{18}$ In fact, xanthines are much less expensive medications than ICS and LABAs, and the use of theophylline was found to be associated with a reduction in exacerbation rate (albeit less effective than ICS) in COPD patients with frequent exacerbations. ${ }^{32}$

Consumption of antileukotrienes in COPD was low, but was greater than expected in view of the fact that their effectiveness in the treatment of this disease is limited. ${ }^{33}$

In conclusion, these results, from a large, validated, population-based database, illustrate real life prescribing in Italy and can be considered representative of the general population. They show a definite, albeit small, change in the approach by GPs to the treatment of COPD, whilst prescribing for asthma seems to be substantially more stable, and there is a modest increase in prescriptions of LABA/ICS fixed combination inhalers. Nevertheless, our study has important limitations, many of which are common to retrospective database analyses. One of 
these limitations is the possible bias towards selection of more highly motivated (or better organised) general practices. However, the HSD data relate to diagnoses for which a relevant medication is prescribed; though this data may underestimate the true prevalence of the disease, it is active current data and the headline diagnosis is severe enough to require pharmacotherapy. Another important weakness of our study is that we had no access to individual patient-level data, so the results are presented as 'whole-population' information. Moreover, our results are based entirely on computerised prescription drug data of prescribed medications; consequently, they may not coincide precisely with the actual intake of medications, potentially resulting in some misclassification of drug use.

\section{Acknowledgements}

This study is based on data from the Health Search database owned by the Italian College of General Practitioners. The interpretation and conclusions contained in this study are those of the authors alone. Access to the Health Search database was offered free by the Italian College of General Practitioners.

\section{Conflicts of interest}

The authors have no significant conflicts of interest with any company or organisation whose products or services are discussed in this article.

\section{Contributorship}

The original idea for the study was formulated by Prof. Cazzola, with subsequent advice from Drs. Bettoncelli and Cricelli, and statistical input from Dr. Calzetta, who also performed the statistical analyses. Prof. Cazzola drafted the manuscript, with extensive contributions and revision from all authors.

\section{Funding}

This study was not funded by any companies or organisations.

\section{References}

1. National Asthma Education and Prevention Program. Expert Panel Report 3 (EPR-3): Guidelines for the Diagnosis and Management of Asthma-Summary Report 2007. I Allergy Clin Immunol 2007;120(5 Suppl):S94-138. http://dx.doi.org/10.1016/j.jaci.2007.09.029

2. Bateman ED, Hurd SS, Barnes PJ, et al. Global strategy for asthma management and prevention: GINA executive summary. Eur Respir J 2008;31:143-78. http://dx.doi.org/10.1183/09031936.00138707

3. Celli BR, MacNee W. Standards for the diagnosis and treatment of patients with COPD: a summary of the ATS/ERS position paper, Eur Respir J 2004;23:932-46. http://dx.doi.org/10.1183/09031936.04.00014304

4. Rabe KF, Hurd S, Anzueto A, et al. Global strategy for the diagnosis, management, and prevention of chronic obstructive pulmonary disease: GOLD executive summary. Am J Respir Crit Care Med 2007;176:532-55. http://dx.doi.org/10.1164/rccm.200703-456so

5. Buist AS. Similarities and differences between asthma and chronic obstructive pulmonary disease: treatment and early outcomes. Eur Respir J 2003;39:30s35s. http://dx.doi.org/10.1183/09031936.03.00404903

6. Cazzola M. Current opinion: Pharmacological approaches in asthma and COPD. Breathe 2009;6:24-35. http://dx.doi.org/10.1183/18106838.0601.024

7. Izquierdo JL, Martín A, de Lucas P, Rodríguez-González-Moro JM, Almonacid C, Paravisini A. Misdiagnosis of patients receiving inhaled therapies in primary care. Int J Chron Obstruct Pulmon Dis 2010;5:241-9.

8. Tinkelman DG, Price DB, Nordyke RJ, Halbert RJ. Misdiagnosis of COPD and asthma in primary care patients 40 years of age and over. I Asthma
2006;43:75-80. http://dx.doi.org/10.1080/02770900500448738

9. Buffels J, Degryse J, Liistro G. Diagnostic certainty, co-morbidity and medication in a primary care population with presumed airway obstruction: the DIDASCO2 study. Prim Care Respir J 2009;18:34-40. http://dx.doi.org/10.3132/pcrj.2008.00047

10. van Schayck CP, van der Heijden FMMA, van den Boom G, Tirimanna PRS, van Herwaarden CLA. Underdiagnosis of asthma: is the doctor or the patient to blame? The DIMCA project. Thorax 2000;55:562-65. http://dx.doi.org/10.1136/thorax.55.7.562

11. van Schayck CP, Chavannes NH. Detection of asthma and chronic obstructive pulmonary disease in primary care. Eur Respir J 2003;21(suppl 39):16S-22S. http://dx.doi.org/10.1183/09031936.03.00040403

12. Tinkelman DG, Price DB, Nordyke RJ, Halbert RJ. Misdiagnosis of COPD and asthma in primary care patients 40 years of age and over. I Asthma 2006;43:75-80. http://dx.doi.org/10.1080/02770900500448738

13. Lucas AE, Smeenk FW, Smeele IJ, van Schayck CP. Overtreatment with inhaled corticosteroids and diagnostic problems in primary care patients, an exploratory study. Fam Pract 2008;25:86-91. http://dx.doi.org/10.1093/fampra/cmn006

14. Jones RC, Dickson-Spillmann M, Mather MJ, Marks D, Shackell BS. Accuracy of diagnostic registers and management of chronic obstructive pulmonary disease: the Devon primary care audit. Respir Res 2008;9:62. http://dx.doi.org/10.1186/1465-9921-9-62

15. Partridge MR. Delivering optimal care to the person with asthma: what are the key components and what do we mean by patient education? Eur Respir J 1995;8:298-305. http://dx.doi.org/10.1183/09031936.95.08020298

16. Rennard S, Decramer M, Calverley PM, et al. Impact of COPD in North America and Europe in 2000: subjects' perspective of Confronting COPD International Survey. Eur Respir J 2002;20:799-805. http://dx.doi.org/10.1183/09031936.02.03242002

17. Caramori G, Bettoncelli G, Carone M, et al. Degree of control of physiciandiagnosed asthma and COPD in Italy. Monaldi Arch Chest Dis 2007;67:15-22.

18. Cazzola M, Bettoncelli G, Sessa E, Cricelli C. Primary care of the patient with chronic obstructive pulmonary disease in Italy. Respir Med 2009;103:582-8. http://dx.doi.org/10.1016/j.rmed.2008.10.017

19. FDA Public Health Advisory. Serevent Diskus (salmeterol xinafoate inhalation powder), Advair Diskus (fluticasone propionate \& salmeterol inhalation powder), Foradil Aerolizer (formoterol fumarate inhalation powder). Updated May 15, 2006. Available at: http://www.fda.gov/cder/drug/advisory/LABA.htm (accessed May 24, 2007)

20. Calverley PM, Anderson JA, Celli B, et al. Salmeterol and fluticasone propionate and survival in chronic obstructive pulmonary disease. N Engl J Med 2007;356:775-89. http://dx.doi.org/10.1056/NEJMoa063070

21. Wedzicha JA, Calverley PM, Seemungal TA, Hagan G, Ansari Z, Stockley RA. The prevention of chronic obstructive pulmonary disease exacerbations by salmeterol/fluticasone propionate or tiotropium bromide. Am J Respir Crit Care Med 2008;177:19-26. http://dx.doi.org/10.1164/rccm.200707-9730C

22. Tashkin DP, Celli B, Senn S, et al. A 4-year trial of tiotropium in chronic obstructive pulmonary disease. N Engl J Med 2008;359:1543-54. http://dx.doi.org/10.1056/NEJMoa0805800

23. Moja PL, Lari C, Trisolini R, Auxilia F. Analysis of some variables concerning guidelines adopted in a hospital in Milan: quantity, quality and physicians' attitude; which is the reciprocal influence of these factors? Eur J Public Health 2003;13:146-51. http://dx.doi.org/10.1093/eurpub/13.2.146

24. Formoso G, Liberati A, Magrini N. Practice guidelines: useful and "participative" method? Survey of Italian physicians by professional setting. Arch Intern Med 2001;161:2037-42. http://dx.doi.org/10.1001/archinte.161.16.2037

25. Lugtenberg M, Zegers-van Schaick JM, Westert GP, Burgers JS. Why don't physicians adhere to guideline recommendations in practice? An analysis of barriers among Dutch general practitioners. Implement Sci 2009;4:54. http://dx.doi.org/10.1186/1748-5908-4-54

26. Herland K, Akselsen JP, Skjønsberg OH, Bjermer L. How representative are clinical study patients with asthma or COPD for a larger "real life" population 
M Cazzola et al.

of patients with obstructive lung disease? Respir Med 2005;99:11-19. http://dx.doi.org/10.1016/j.rmed.2004.03.026

27. Simoni M, Carrozzi L, Baldacci S, et al. Respiratory symptoms/diseases, impaired lung function, and drug use in two Italian general population samples. Respir Med 2008;102:82-91. http://dx.doi.org/10.1016/..rmed.2007.08.002

28. Bottema BAM. Diagnostiek van CARA in de huisartspraktijk. (Diagnosis of chronic a-specific respiratory morbidity in general practice). Dissertation: University of Amsterdam, Amsterdam, 1993. [summary in English]

29. Nelson HS, Scott TW, Bleecker ER, Yancey SW, Dorinsky PM. The Salmeterol Multicenter Asthma Research Trial: a comparison of usual pharmacotherapy for asthma or usual pharmacotherapy plus salmeterol. Chest 2006;291:15-26. http://dx.doi.org/10.1378/chest.129.1.15

30. Aaron SD, Vandemheen $\mathrm{KL}$, Fergusson $\mathrm{D}$, et al. Tiotropium in combination with placebo, salmeterol, or fluticasone-salmeterol for treatment of chronic obstructive pulmonary disease: a randomized trial. Ann Intern Med 2007; 146:545-55

31. Blais L, Bourbeau J, Sheehy O, LeLorier J. Inhaled corticosteroids in COPD: determinants of use and trends in patient persistence with treatment. Can Respir J 2004;11:27-32.

32. Cyr MC, Beauchesne MF, Lemière C, Blais L. Effect of theophylline on the rate of moderate to severe exacerbations among patients with chronic obstructive pulmonary disease. $\mathrm{Br} J$ Clin Pharmacol 2008;65:40-50. http://dx.doi.org/10.1111/j.1365-2125.2007.02977.x

33. Rubinstein I, Kumar B, Schriever C. Long-term montelukast therapy in moderate to severe COPD - a preliminary observation. Respir Med 2004;98:134-8. http://dx.doi.org/10.1016/j.rmed.2003.09.003

Available online at http://www.thepcrj.org

\section{IPCRG membership - could you follow their lead?}

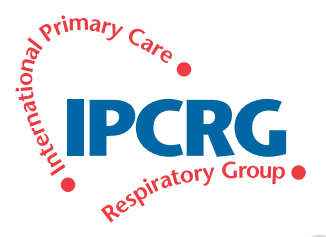

The IPCRG supports the development of new national primary care groups with a shared interest in respiratory care.

They can then join us as associate members, and once established, as full members.
Here are some recent activities from our membership:

In early May GRAP, the Spanish group held its second meeting in Barcelona with more than 90 attendees from all over Spain. Highlights included multidisciplinary presentations on informatics to support disease management and patient-centred care, new pharmacological evidence and new tests for pulmonary function. GRAP is also involved in producing innovative Spanish phenotype-based guidelines on COPD management (gesEPOC) due to be launched very soon.

The same weekend, 150 primary care professionals from our Nordic groups attended a joint Nordic conference.

To observe World Asthma Day 201 1, our Associate Member in Kolkata, the Indian Primary Respiratory Care \& Allergy Foundation (IPRCAF), organised a walk for about 400 school pupils, staff at one of the local health clinics and members of Lions Clubs International. There were also medical education sessions for over 100 doctors and discussions about the burden of asthma, air pollution and urgent need for appropriate public education to alleviate the debilitating fear of an asthma diagnosis and using an inhaler.

Our Dutch group, CAHAG, is helping deliver a European Respiratory Society Primary Care Day on Saturday 24 September at which many IPCRG colleagues are speaking. You can view the programme in this issue of the PCRJ on page 346. Do go!

\section{To find out more about membership, contact our Business Manager, Sam Louw BusinessManager@theipcrg.org and visit our website: http://www.theipcrg.org/members/index.php}

